九州大学学術情報リポジトリ

Kyushu University Institutional Repository

\title{
Verification of Hydraulic Equivalence during Clastic Sedimentation: Examples from Tephra Fallout and Sandstones
}

Miyata, Yuichiro

Environmental Geology Department, Geological Survey of Japan

https://doi.org/10.5109/1546559

出版情報：九州大學理學部紀要：Series D, Geology. 26 (3)，pp.243-263，1989-12-20. Faculty of Science, Kyushu University バージョン:

権利関係 : 
Mem. Fac. Sci., Kyushu Univ., Ser. D, Geol., Vol. XXVI, No. 3, pp. 243-263, text-figs. 1-15, tables 1-2, December 20, 1989

\title{
Verification of Hydraulic Equivalence during Clastic Sedimentation
}

\author{
- Examples from Tephra Fallout and Sandstones -
}

\author{
Yuichiro MIYATA*
}

\begin{abstract}
The pronounced correlation between mineral composition and grain-size in sedimentary deposits is attributed to hydraulic sorting during transportation. The hydraulic equivalence is realized in the form that the mineral composition of grains in a fixed settling velocity interval is maintained constant during the transportation by suspension. One of the Quaternary pyroclastic fall deposits in Hokkaido, Spfa-1 is wide-spread and shows a remarked lateral textural variation. The settling velocity of constituent grains such as pumice, lithic and free crystals were measured in relation to grain size. And the mineral composition in a fixed velocity interval was proved to be almost constant at every points along the disposal line.

This result was applied to two different Cretaceous sandstone formations in Hokkaido. The modal and textural analyses showed that the turbidite sandstones from the Kanayama area have had a distinct grain-size-controlled variation, while those of the other shallow-marine sandstones from the Furano area was variable and less size-controlled. The former variation pattern can be interpreted to have been resulted from hydraulic sorting on primarily well-mixed, homogenized source. These modal variation patterns give useful information on the mode of transportation and on the homogeneity of the source material.
\end{abstract}

\section{Introduction}

Constituent grains in sediments vary in size, density and shape. It is expected that all of the grains with the same settling velocity show the same behavior and are discriminated from grains with different velocities in a suspension load due to hydraulic sorting (Carver, 1971; Slingerland, 1977). This relationship among different grains is called "hydraulic equivalence" (H. E.) by Rubey (1933).

If $\mathrm{H} . \mathrm{E}$. is realized in sediments during transportation, it can be expected that constituent grains, which have different densities and shapes, show the same settling velocity or the same settling velociy distributions when the variation due to turbulence in a fluid flow was involved.

Many investigations on the settling velocity show, however, that the above relationship is not realized in natural sediments (e.g. Hesse, 1965; Folk, 1974). This is attributed to two main causes which are independent with each other. One is that H. E. can not be realized in the traction load among grains of differ-

\footnotetext{
* Present address: Environmental Geology Department, Geological Survey of Japan, Higashi 1-1-3, Tsukuba, Ibaraki 305

Manuscript received August 2, 1989
} 
ent densities and shapes. When smaller and heavier grains creep in lower boundary layer, lighter and larger ones of the same settling velocity tend to move into an upper boundary layer by saltation.

Secondly, the relative availability of the constituents has not been counted into H. E. . The availability has often been slighted, or ignored because it is usually be difficult to estimate. The relative abundance of grains with a certain settling velocity should be affected by both selective sorting in a fluid flow and relative availability. In other words, it is given by the product of the above two probabilities. Consequently, in order to know whether H. E. is realized or not, it is not enough to compare the settling velocity distributions among different constituent minerals.

This paper investigates how hydraulic sorting leads to compositional variation in suspension load of Quaternary pyroclastic fall deposits, and H. E. is applied to the variation in Cretaceous sandstones.

\section{Consistency of Fractional Composition}

Grains of the same settling velocity can not be distinguished from each other in suspension during transportation when $\mathrm{H}$. E. is realized. The mineral compositions of the grains with the same settling velocity are, therefore, maintained anywhere during transportation and deposition. When this modal consistency is realized in sediments, it may indicate that $H$. E. is realized during transportation.

The sediments suitable for testing the above hypothesis should satisfy the following conditions;

(1) derived from a common source,

(2) transported by suspension,

(3) keep their original textures.

Among natural clastic deposits, one of the most suitable for testing is a pyroclastic fall deposit. Because it is derived from an instantaneous point source, every deposit undoubtedly has the common source. It is transported upward in the eruption culumn and laterally downwind by suspension. The Quaternary tephra named the Shikotsu Pumice Fall Doposit -1 (Spfa-1, 32,000 y.B.P.) in Hokkaido, Japan, is one of such examples and was selected for this test. It is also one of the most widespread and well-documented deposits in Japan (Machida and Arai, 1976; Katsui, 1959). Because it is neither consolidated nor altered, its original composition and the texture can reasonably be examined.

\section{Material and Method}

\section{A. Textural and modal analyses}

Spfa-1 tephra plume expands eastward over $170 \mathrm{~km}$ from the Shikotsu volcano to the Cape Erimo (Fig. 1; Committee on Nomenclature of Pyroclastic Deposits in Hokkaido, 1972, 1982). The thickness and the maximum clast size systematically decrease downwind (Fig. 1; Katsui, 1959). Fifteen samples were studied along its dispersal axis. Grain size distributions of these samples, 

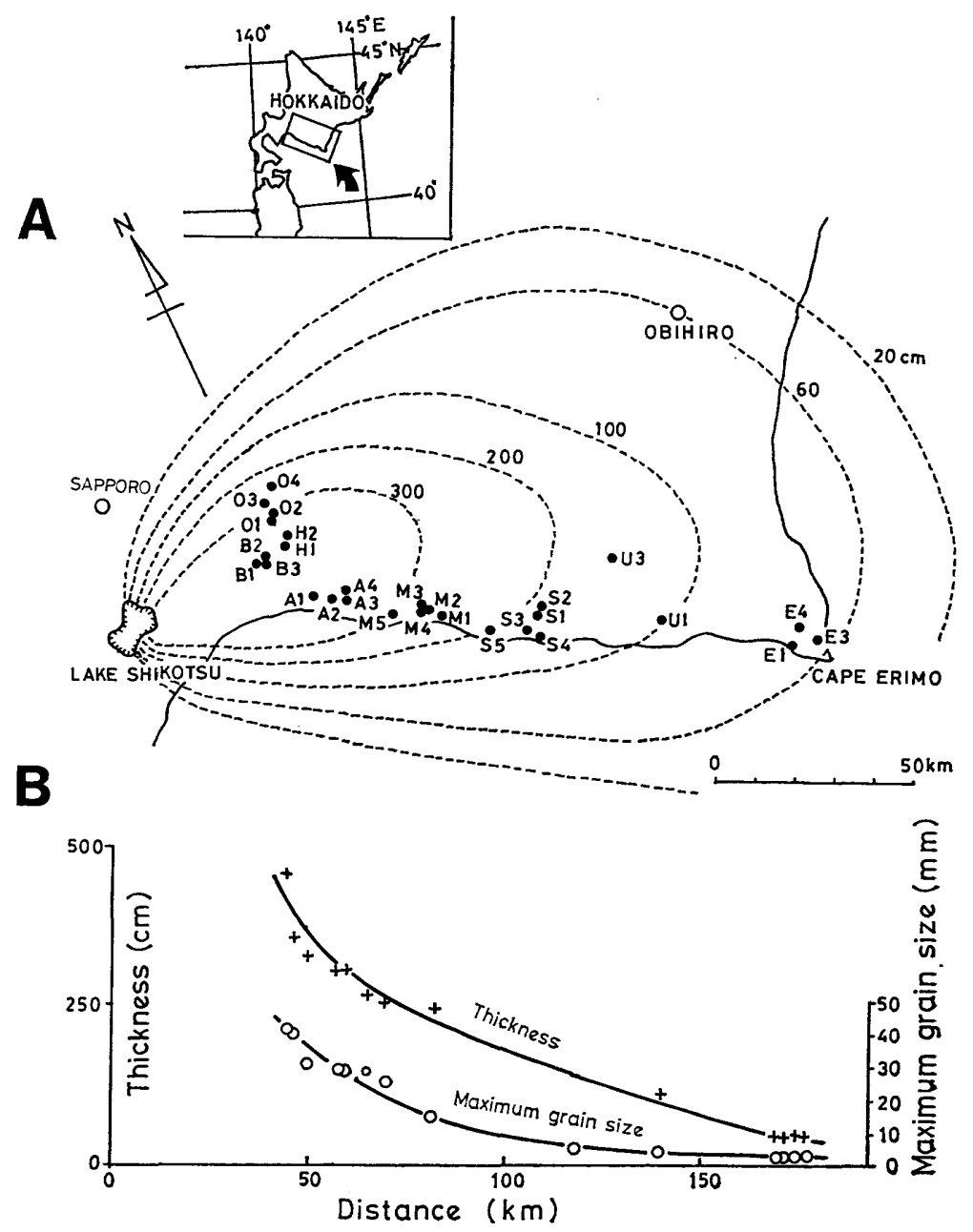

Fig. 1. Distribution of the Spfa-1 deposits (after Katsui, 1959; Committee on Nonmenclature of Pyroclastic Deposits in Hokkaido, 1972, 1982) with sampling locations for this study (A), and thickness (cross) and maximum grain-size (circle) versus distance from the source volcano (B) (Katsui, 1959).

analyzed by sieving at every 0.5 phi interval, show a significantly finer and better sorted trend away from the vent (Fig. 2). This trend is similar to those reported by Fisher (1964), Walker and Croasdale (1971), Kittleman (1973), Walker (1971) and Sparks et al. (1981) from other areas. At any location, Spfa-1 tephra is rather homogeneous and its internal sedimentary structures can scarcely be observed. The grain-size distribution of samples collected from different positions of a single outcrop shows no remarkable variation. Vertical grading is less significant than the laterhal variation (Fig. 3).

Mineral compositions were obtained for all size fractions. For grains less than $2 \mathrm{~mm}$ in diameter, constituent mineral particles were counted under a polarized microscope. Grains of the Spfa-1 are composed of pumice, which is 


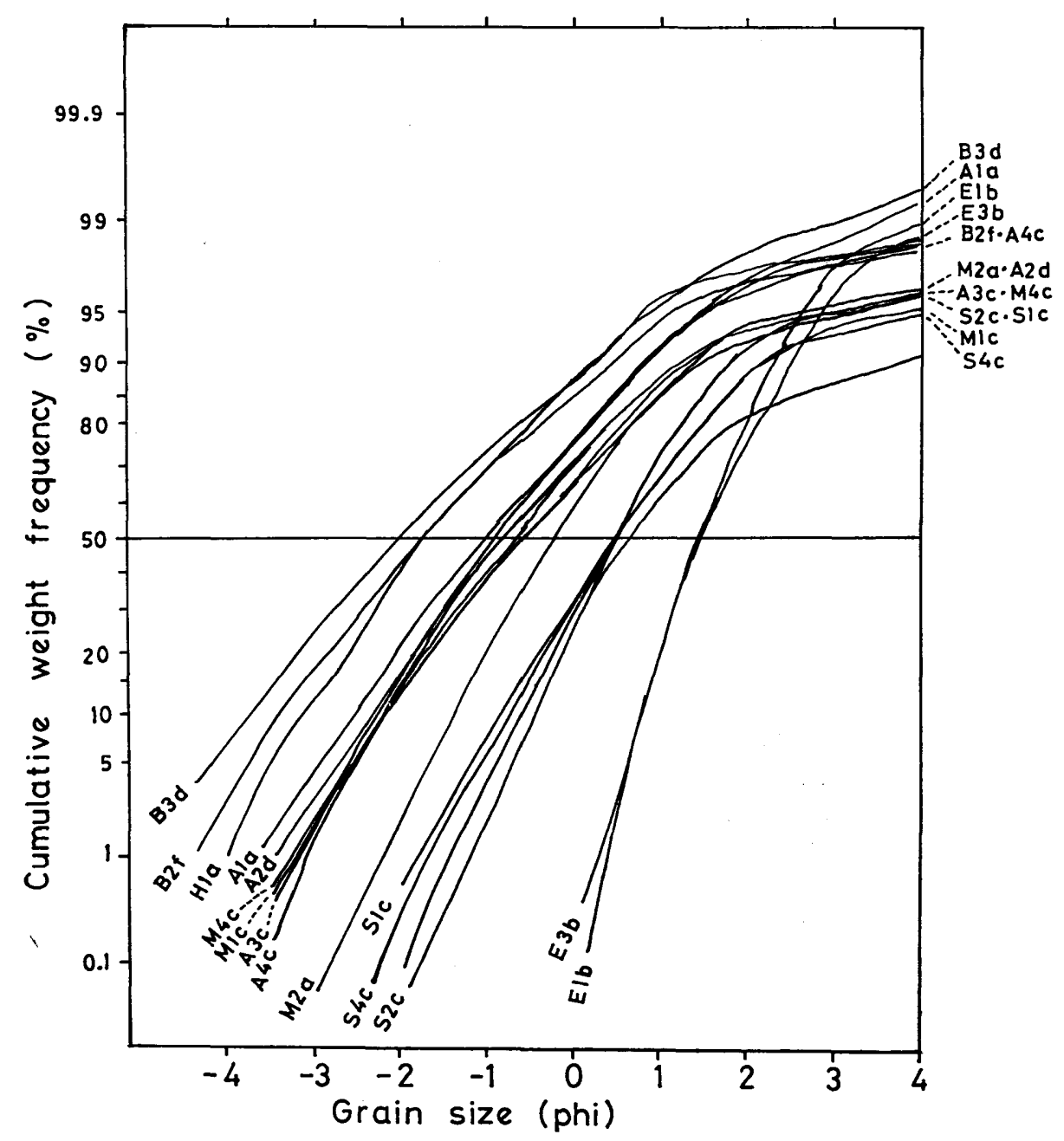

Fig. 2. Weight-frequency grain-size distributions of samples from Spfa-1 tephra.

most abundant exceeding $80 \mathrm{wt} \%$, lithic fragments, free crystals such as feldspar, ortho-pyroxene, clino-pyroxene, hornblende, opaque minerals (mostly magnetite) and glass fragments. The frequency abundances were shown by weight percent. As the density of pumice particle varies with size, the volume of pumice was measured grain by grain with an air-balanced pycnometer after coating with paraffin wax (Table 1). The obtained composition (wt\%) of the 15 samples showed a lateral variation (Fig. 4). For example, pumice grains occur less frequently in the area between 40 to $100 \mathrm{~km}$ from the source, and is counterbalanced by crystalline grains.

\section{B. Settling velocity}

The settling velocity of irregular-shaped particles in the atmosphere can be estimated from drag coefficient (DC) in relation to Reynolds number ( $R e$ ). To 


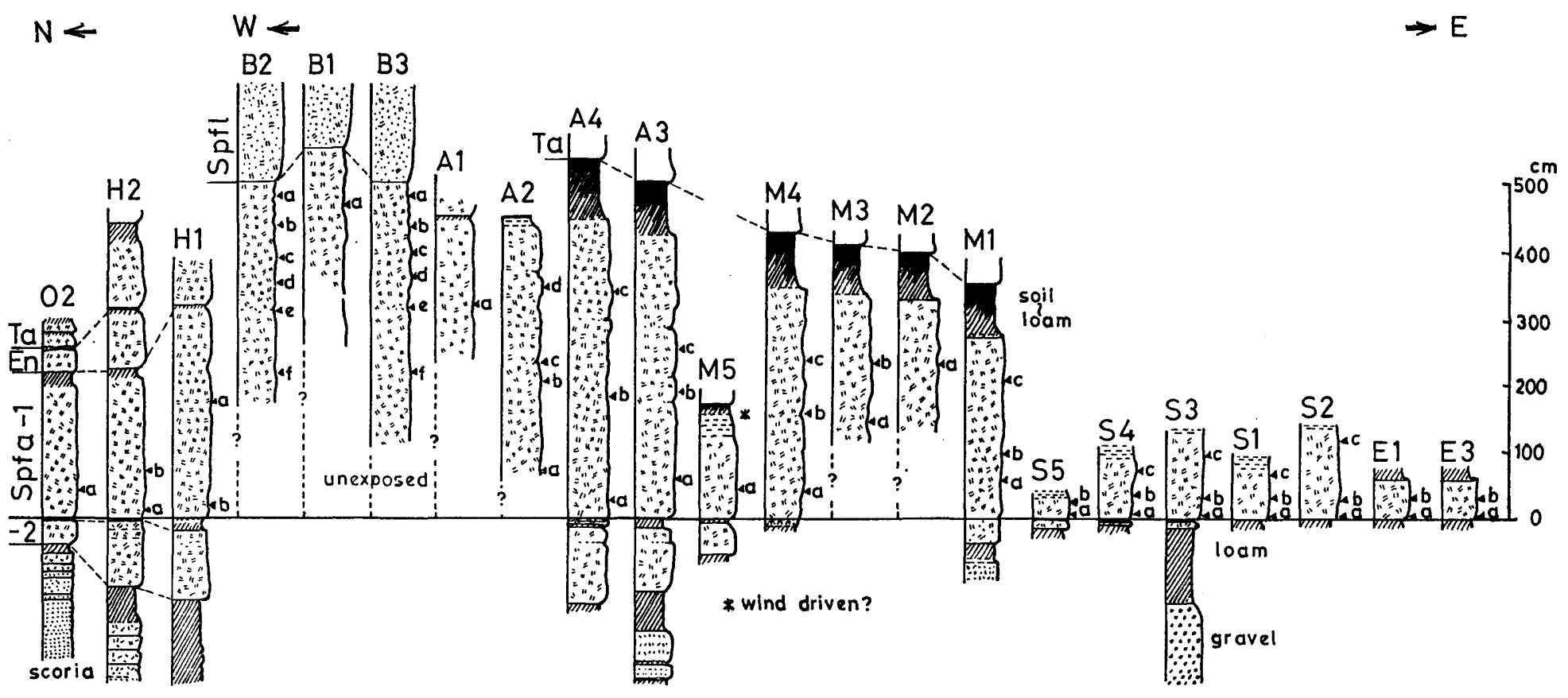

Fig. 3. Columnar sections of Spfa-1 tephra at sampling localities noted in Fig. 1. Lithology symbols are captioned for selected representatives. Tephras such as Shikotsu Pumice Flow deposits(Spf), Eniwa-a(En) and Tarumai-b(Ta) are also shown. Sample numbers $(a, b, \ldots)$ are postfixed to the location numbers (O2a, H2a, ...). 
Table 1. Bulk density of pumice grains $\left(\mathrm{g} / \mathrm{cm}^{3}\right)$ in relation to grain-size.

\begin{tabular}{|cc|}
\hline $\begin{array}{c}\text { grain size } \\
(\phi)\end{array}$ & $\begin{array}{c}\text { apparent density } \\
\left(\mathrm{g} / \mathrm{cm}^{3}\right)\end{array}$ \\
\hline-2.0 & 0.74 \\
-1.5 & 0.75 \\
-1.0 & 0.75 \\
-0.5 & 0.75 \\
0.0 & 0.75 \\
0.5 & 0.75 \\
1.0 & 0.80 \\
1.5 & 1.1 \\
2.0 & 1.4 \\
2.5 & 1.7 \\
3.0 & 1.9 \\
3.5 & 2.0 \\
\hline
\end{tabular}

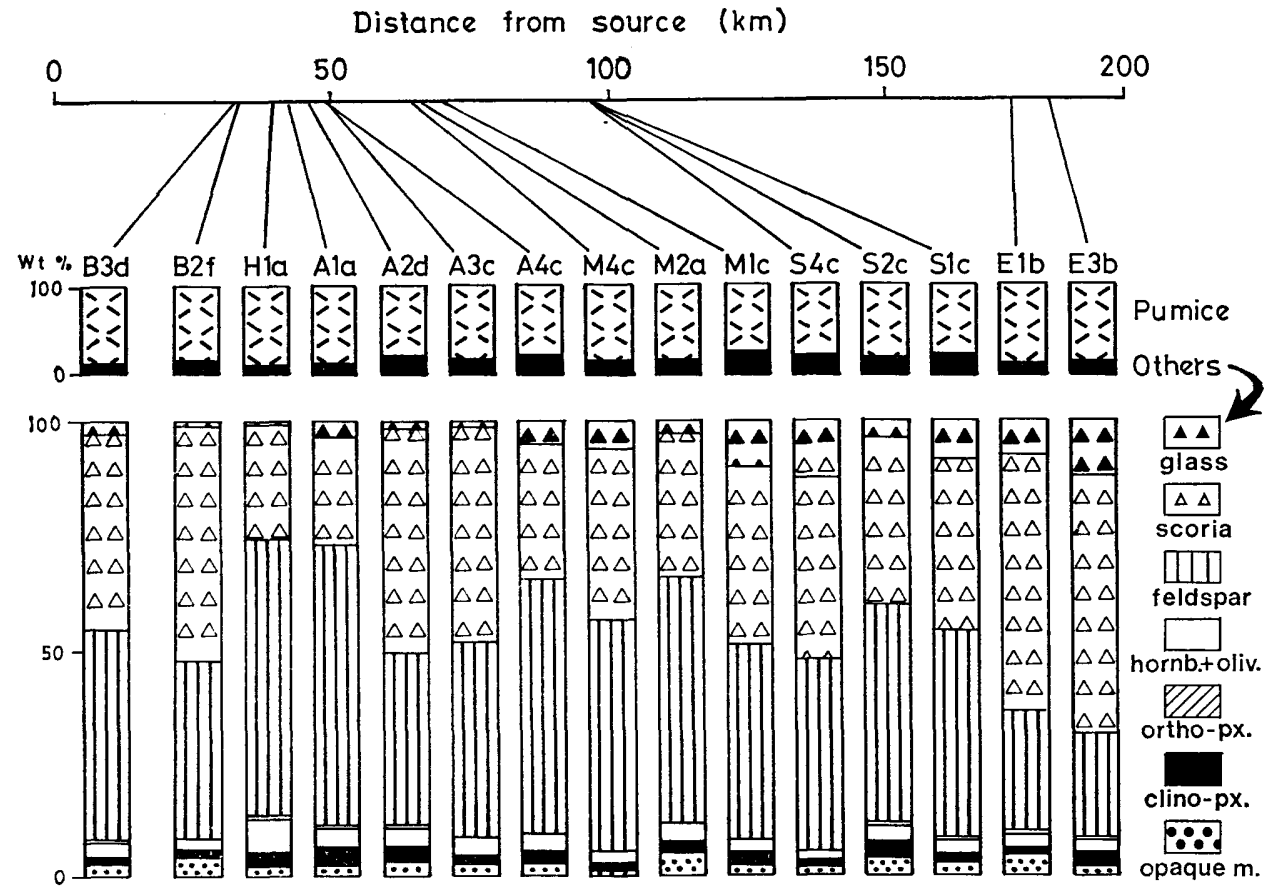

Fig. 4. Mineral compositions (Wt\%) of samples collected from Spfa-1. The upper columns show ratios of pumice to other kinds of ash particles. The lower shows mineral compositions of samples except for pumice.

obtain this relationship for Spfa-1 particles, settling experiments were done. Based on the method by Walker et al. (1971) and Wilson and Huang (1979), particles falling in the air were photographed by a stroboscope. The fall time and distance necessary to reach $99 \%$ of the terminal velocity were estimated 


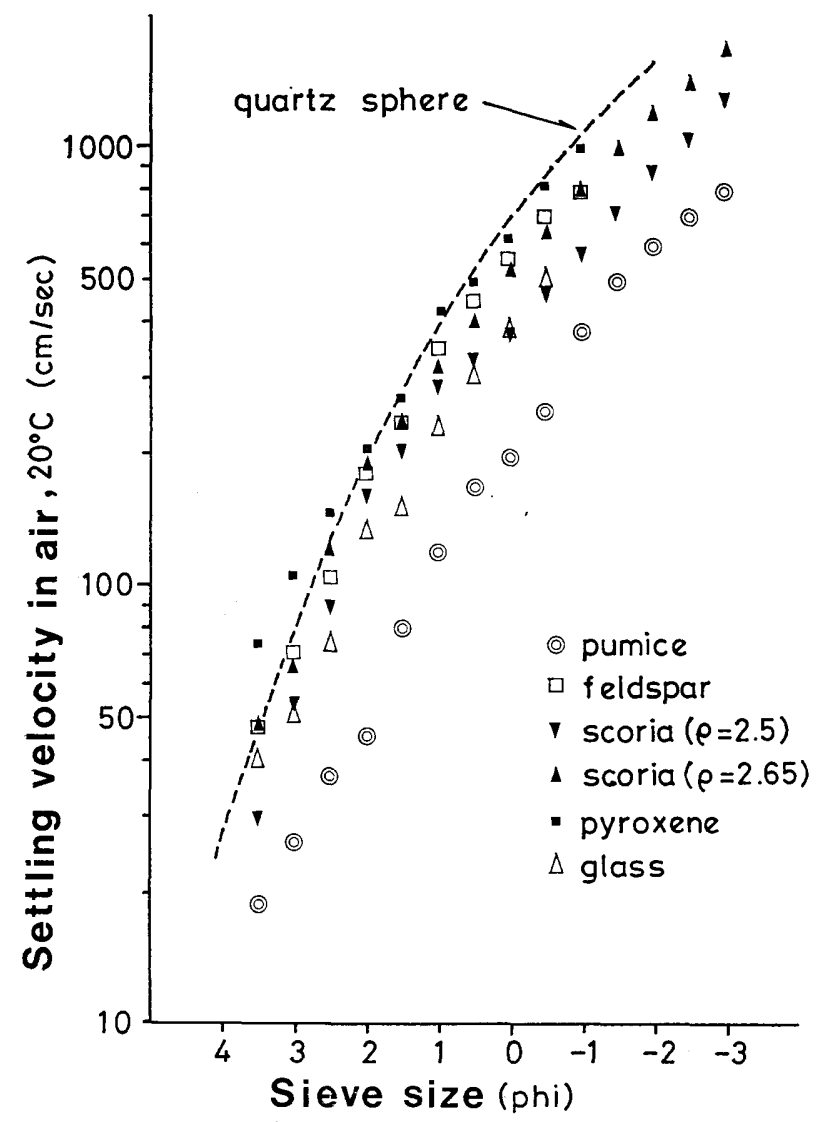

Fig. 5. Experimental results of terminal settling velocity for each mineral species in relation to grainsize. Dashed line indicates calculated relationship using data from (Rouse, 1938) for spheres with density of 2.65 .

from their sizes and densities in advance to this experiment. The mean settling velocities of the constituent minerals in relation to their sizes were obtained as Fig. 5. This relationship can be stated in terms of DC and Re (Fig. 6). The irregularly-shaped particles such as pumice show higher DC values as compared with smooth and equant particles. From these data, the settling velocity at a given altitude in the atmosphere can be estimated using the method proposed by Mitzmager et al. (1964).

According to Katsui and Murase (1960), the maximum height of the Spfa-1 eruption column was estimated at $45 \mathrm{~km}$. The volcaniclastic grains are blown up from the vent in a gas thrust region (Woods, 1988), and driven upward by the buoyancy force in an eruption column. When the cloud reached to the altitude of neutral buoyancy, it becomes umbrella-shaped and travel downward. Because the air in higher altitude is less dense and more viscous due to lower temperature, the fall velocities of Spfa-1 particles which is measured experimentally are different from those expected in the atmosphere where the Spfa-1 particles 


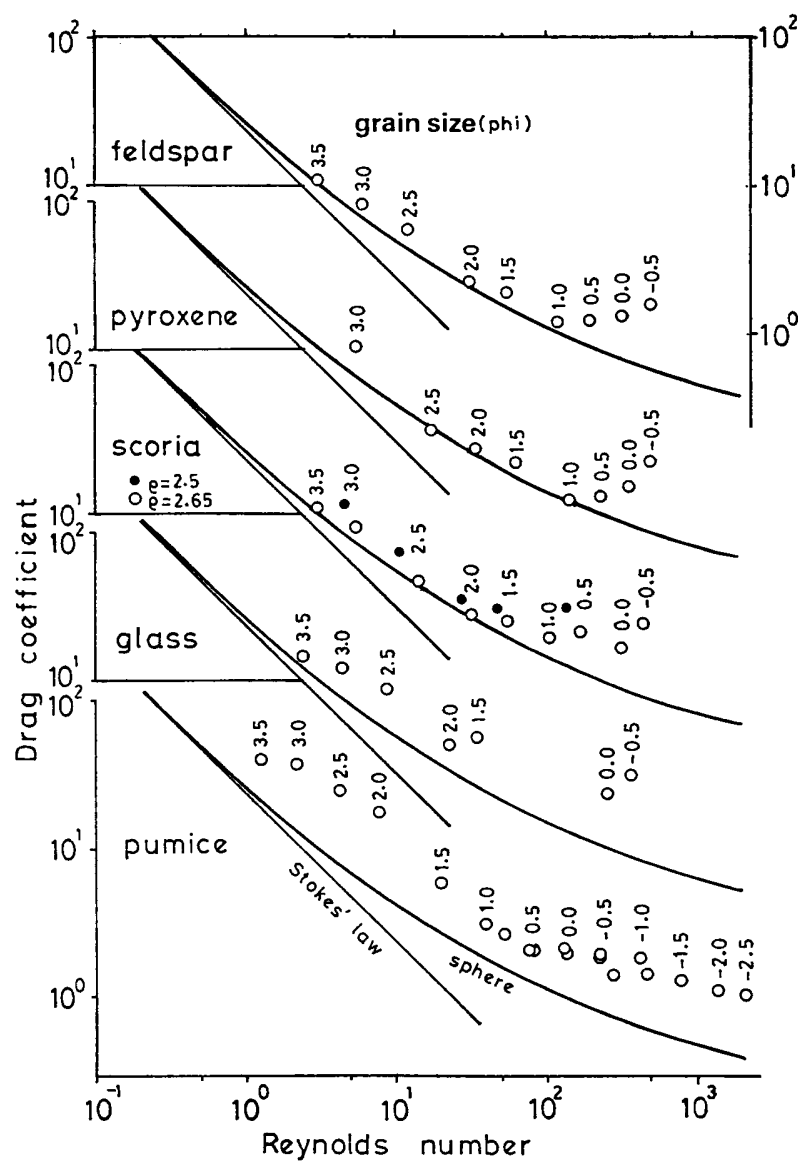

Fig 6. Relationships between drag coefficient (DC) and Reynolds number ( $R e$ ) obtained from terminal settling velocities in air for mineral species in Fig. 5.

traveled. In order to estimate the fall velocity of Spfa-1 particles at various altitudes, we must know the DC values at various Re values, and density and viscosity of the air at various altitudes. For spherical particles, the empirical relationship between DC and Re had been shown in some literatures (e.g. Rouse, 1938). Fig. 7 shows these velocities at various altitudes in the U.S. Standard Atmosphere. In the region of higher Re than the region of Stokes' law, where the majority of Spfa-1 particles travel, the terminal fall velocity increases with altitude, because of less resistance due to lower air density. The rate of velocity increase with the altitude is higher for larger grains. It is also expected that the lighter and larger grains fall faster than finer and denser grain in the upper atmosphere if they both have the same settling velocity at the ground surface level, because they have different Re values in the upper atmosphere. Such a difference is almost negligible for finer grains, but is rather significant for coarser grains. 


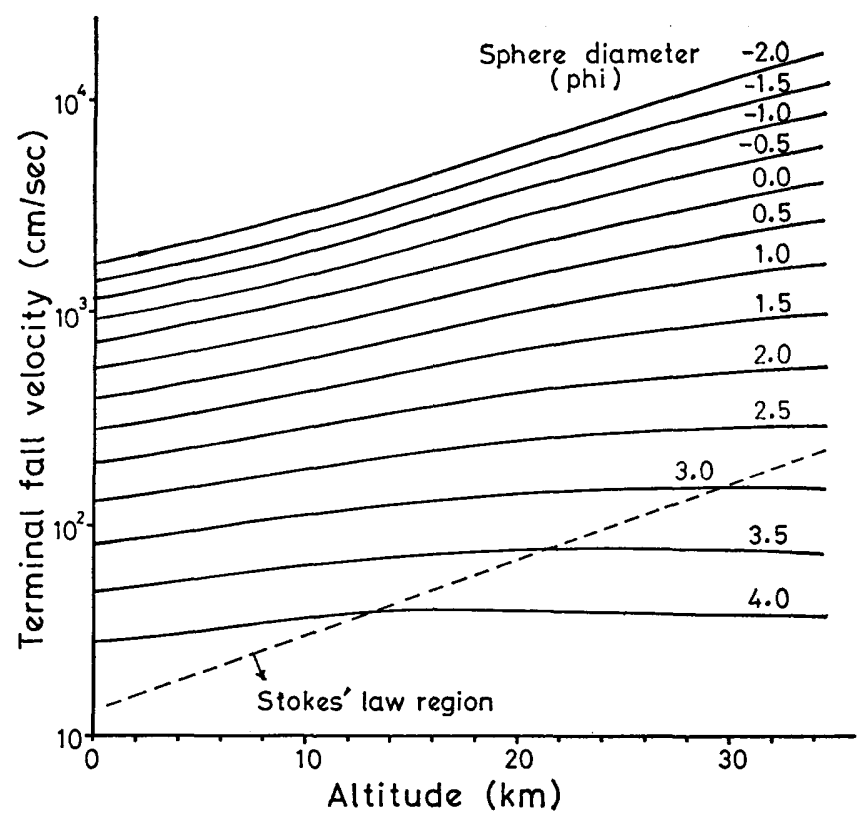

Fig. 7. Terminal settling velocities of quartz spheres of various diameter in the U.S. Standard Atmosphere. Line on which the Reynolds number equals to 1 for flow around the sphere is also shown (dashed line).

However, the coarser grains can not usually be entrained to higher altitude as finer grains in an eruption column. Consequently, the intensity of velocity increase with altitude may be comparable for each size, and there will be no precarious problem when we use the velocity values at the ground level.

\section{Results}

In order to examine how the settling velocity of one constituent differs from that of other in a sample, the settling-velocity distributions were calculated. These were given by the combination of the grain size distribution and the mean settling velocity of every size interval and shown in Fig. 8 . The settling velocity distributions of pumice, feldspar and pyroxenes are similar in some samples (e.g. B2f and A4c), but are significantly different in other samples. According to Fig. 8, pumice shows higher velocity than others in the area proximal to the vent and shows lower velocity downward. From the conventional viewpoint (e.g. Rittenhouse, 1943), it seems likely that H. E. was not realized.

As mentioned before, the consistent composition in a fixed velocity interval can prove H. E. . Fig. 9 shows the comparison of composition in every velocity interval between samples from Spfa-1. Here the settling velocity is presented in $\tau$ unit, where $\tau$ is given by the common logarithm of the velocity in $\mathrm{cm} / \mathrm{sec}$ (Taira and Scholle, 1977). Since pumice occupies more than $90 \%$ in any sample, only the interval between 90 and $100 \%$ is displayed in Fig. 9 to show mineral 


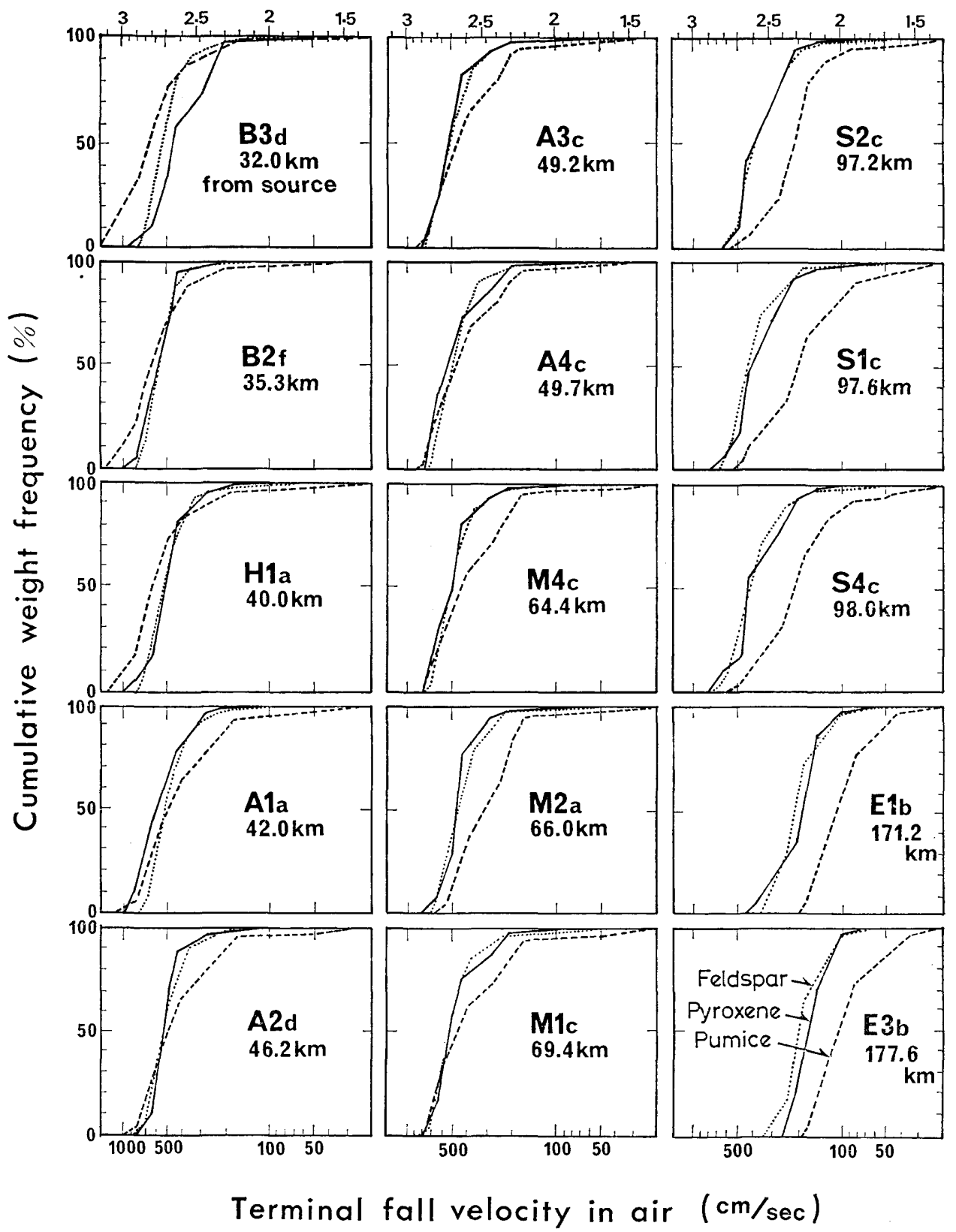

Fig. 8. Cumulative frequency distribution of settling velocity of feldspar, pyroxene, and pumice grains in every sample of Spfa-1. These are arranged from proximal to distal in vertical columns from upper left to lower right. Note that the distributions of three mineral species are dissimilar with each other. Scale on the top is in $\tau(\tau=\log \mathrm{v})$.

compositions explicitly. There is a slight but evident systematic variation with the distance. This is well observed in the velocity intervals from 2.3 to $2.8 \tau$. The crystalline grains become predominant distally, which can be attributed to 


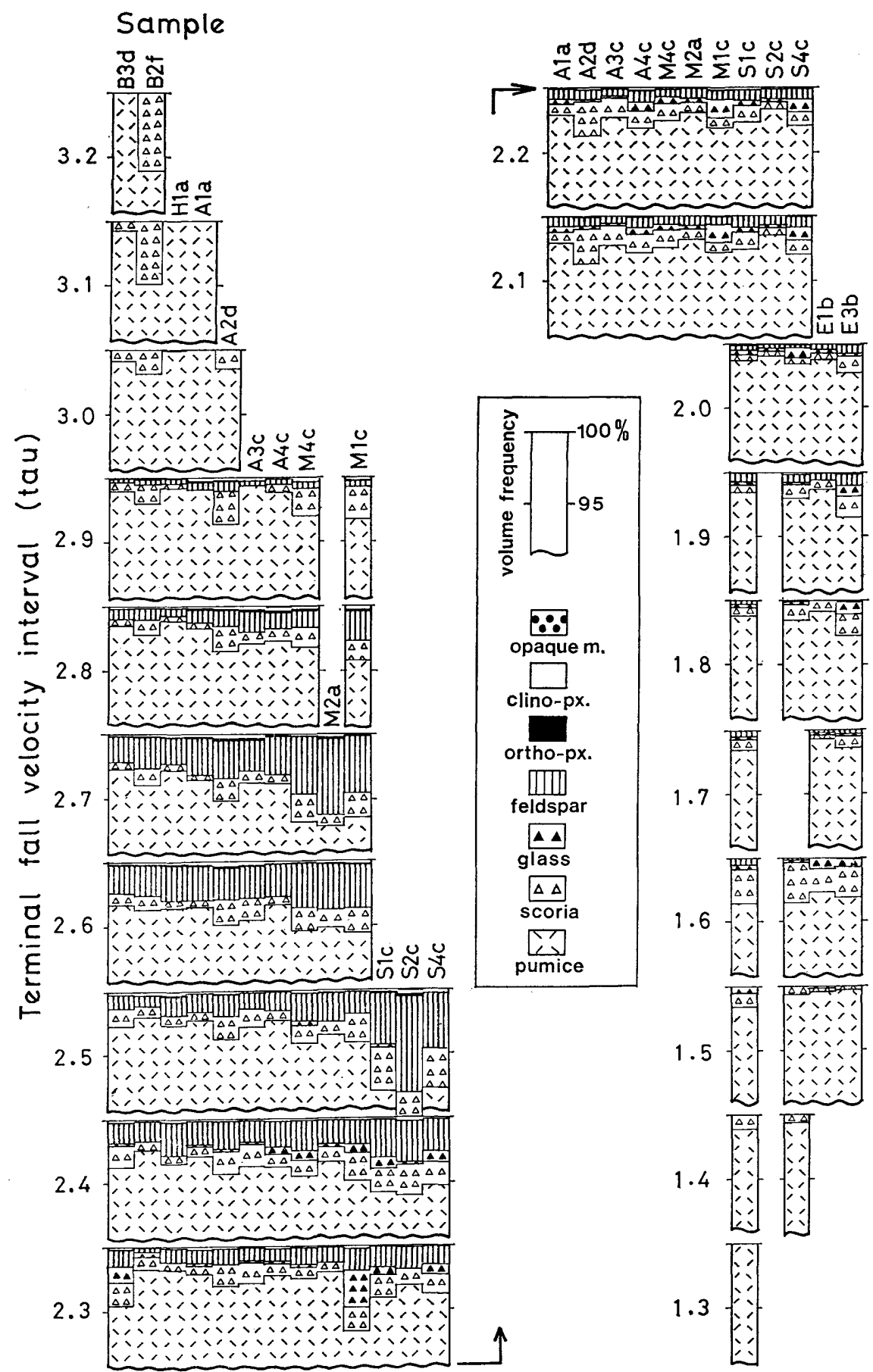

Fig. 9. Mineral compositions of grains in every settling velocity interval of Spfa-1 samples. 
the above-mentioned diversely increased velocity in the atmosphere. Except for this minor drift, it is apparent that the compositional variation with distance in a fixed velocity interval is almost negligible compared to the variation with velocity in a single sample. The mineral composition in a fixed velocity interval was verified to be nearly constant during transportation of Spfa-1 tephra.

These lines of evidence can attest the H. E., and it is also shown that the Spfa-1 tephra fallout satisfied the conditions in which H. E. was realized.

\section{Application of "H.E." to Sandstones}

When H. E. is realized as indicated by the consistent composition in a fixed velocity interval, it is regarded that the sediments were derived from a common source and transported by suspension. Therefore, such a consistent composition is informative about source material and mode of sedimentation as well.

Table 2. Petrographic characteristics of the F1 sandstones and the K2 sandstones. M0: graphic mean size and S.D.: inclusive graphic standard deviation, based on number-frequency and chord length.

\begin{tabular}{|c|c|c|c|}
\hline & & F1 sandstone & K2 sandstone \\
\hline \multirow{4}{*}{ 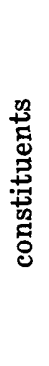 } & quartz & $\begin{array}{l}\text { non-undulose volcanic quartz } \\
\text { and undulose polycrystalline } \\
\text { quartz }\end{array}$ & $\begin{array}{l}\text { polycrystalline and microcrys- } \\
\text { talline quartz predominant }\end{array}$ \\
\hline & feldspar & $\begin{array}{l}\text { microcline more than the half } \\
\text { of total K-feldspar, plagioclase } \\
\text { and perthite }\end{array}$ & $\begin{array}{l}\text { microcline, microcline-perthite } \\
\text { and plagioclase }\end{array}$ \\
\hline & rock-fragments & $\begin{array}{l}\text { volcanic rocks and older clastic } \\
\text { sedimentary rocks }\end{array}$ & $\begin{array}{l}\text { chert fragment predominant, a } \\
\text { few older clastic sedimentary } \\
\text { rocks, and volcanic rocks }\end{array}$ \\
\hline & accessory & $\begin{array}{l}\text { micas, opaque minerals and } \\
\text { zircon }\end{array}$ & $\begin{array}{l}\text { micas and few radiolarian re- } \\
\text { mains in clay matrix }\end{array}$ \\
\hline \multirow{2}{*}{ 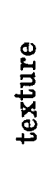 } & particle size & $\begin{array}{l}\text { medium to fine }(\mathrm{M} \emptyset=3.17 \pm 0.47) \\
\text { moderately to poorly sorted } \\
\text { (S.D. }=1.01 \pm 0.11)\end{array}$ & $\begin{array}{l}\text { coarse to fine }(\mathrm{M} \emptyset=2.47 \pm 0.47) \\
\text { moderately to poorly sorted } \\
\text { (S.D. }=0.87 \pm 0.08)\end{array}$ \\
\hline & $\begin{array}{l}\text { shape } \\
\text { fabric }\end{array}$ & $\begin{array}{l}\text { subangular to subrounded } \\
\text { random }\end{array}$ & $\begin{array}{l}\text { subrounded } \\
\text { almost random }\end{array}$ \\
\hline
\end{tabular}

This conception was applied to Cretaceous sandstones. Petrographical analyses were made for two marine formations of the Lower Yezo Group (approximately Aptian to Middle Albian in age according to Obata and Matsumoto, 1977), the F1 (Tomitoi) Formation and the K2 Formation in Kanayama, central Hokkaido (Fig. 10).

The F1 Formation is locally called the Tomitoi Formation and consists of thick-bedded to massive, medium-grained sandstone beds occasionally with many plant fragmental remains and little amounts of mudstone (Fig. 11). Lateral continuity of the sedimentary layer is rather poor and the beds occasionally pinch out. Thickness varies from $250 \mathrm{~m}$ to $400 \mathrm{~m}$ in the Furano area. The K2 Formation ( $250 \mathrm{~m}$ thick) is represented by rhythmic alternation of turbidite fan facies and intercalated pebbly mudstones (Fig. 11). Sandstone bed, usually less than $30 \mathrm{~cm}$ in thickness, is predominant over black shale in most outcrops. 


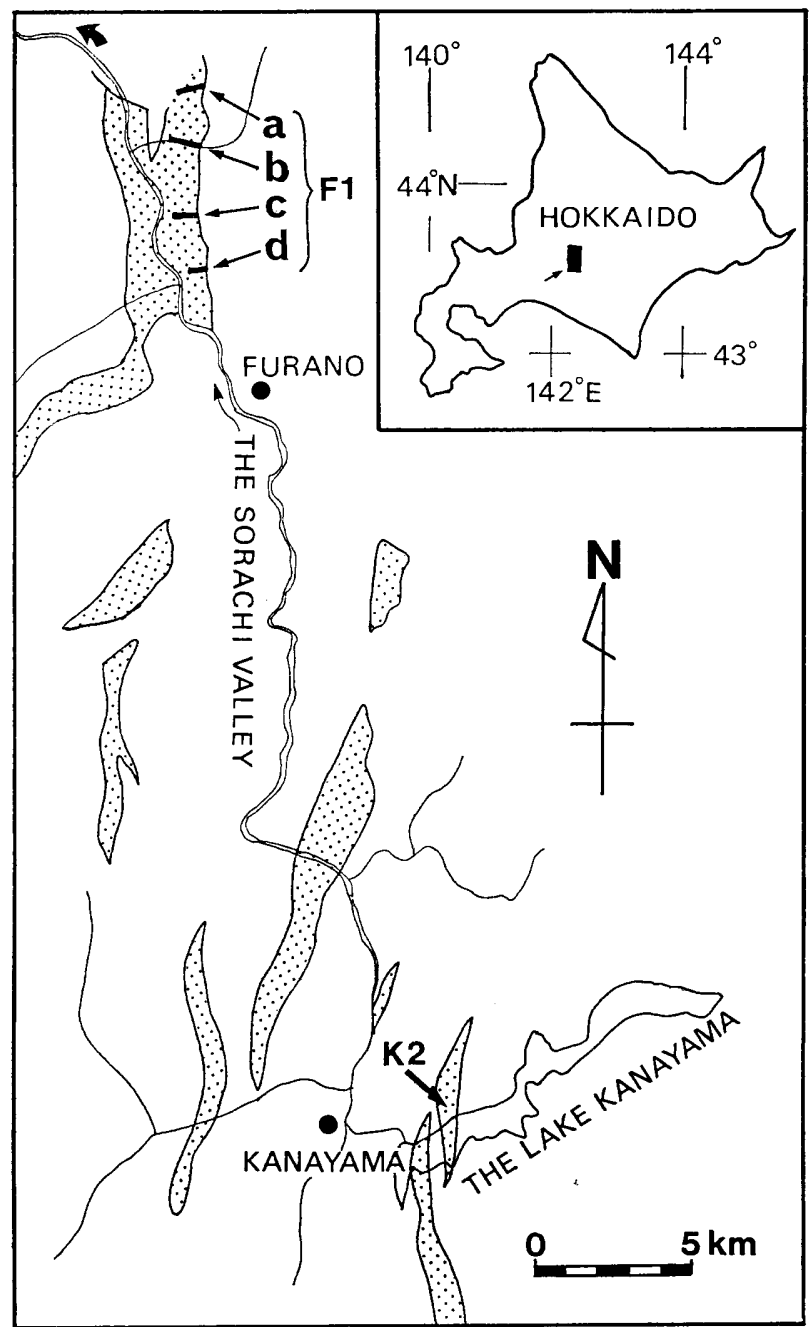

Fig. 10. Map of the Furano-Kanayama area, central Hokkaido, showing the distribution of the Cretaceous Lower Yezo Group (dotted) and the survey routes.

\section{A. Grain size control on mineral compositions}

Samples without any sort of alteration, weathering and authigenic overgrowth were used for both modal and textural examinations. As these sediments were consolidated and cemented, it is difficult to obtain the settling velocity for every constituent minerals. The sandstones from these formations are composed mostly of quartz, feldspar and lithic fragments. These constituents are similar in shape and density with each other, and these mineral grains with the same grain-size will show considerably similar settling velocity. Therefore, mineral composition in a fixed size interval can be used to examine $H$. E. instead of that in a fixed velocity interval. The grains of the same size may not be distinguished among others even in a traction load as well as in a suspension load. Since the 


\section{F1 Formation}
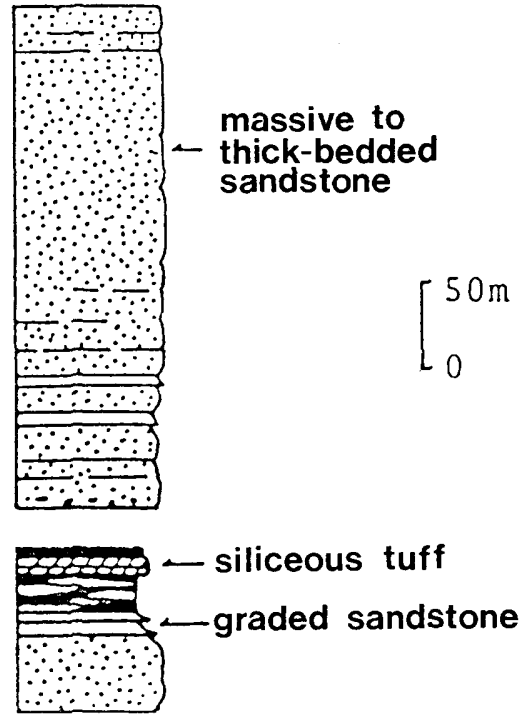

K2 Formation

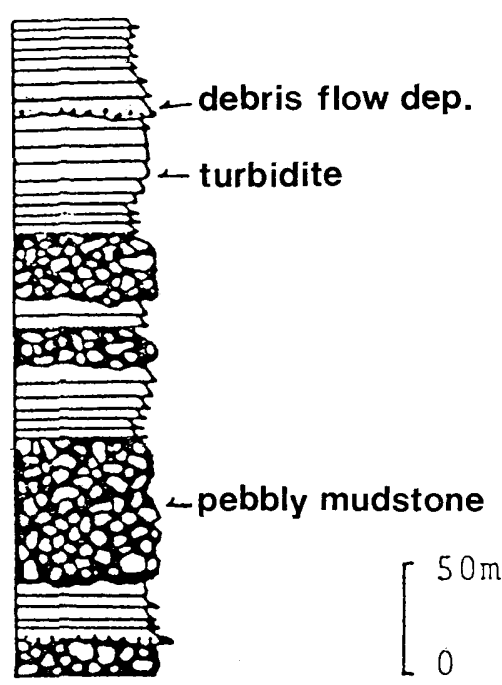

Fig. 11. Lithological columnar sections of the F1 formation (left) along the route b in Fig. 10 in the Furano area and that of $\mathrm{K} 2$ (right) in the Kanayama area.

F1

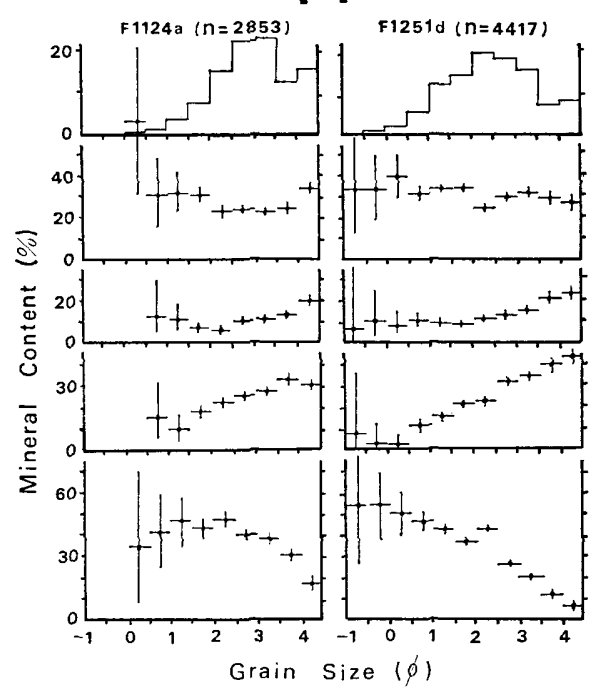

K 2

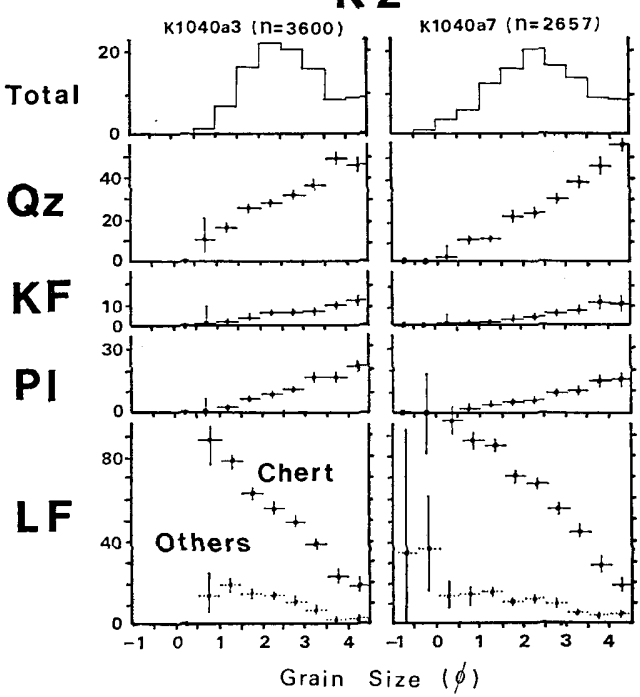

Fig. 12. Modal abundances of minerals and lithic fragments in relation to grainsize in selected samples from F1 sandstones (left) and those from K2 sandstones (right). Qz: quartz, KF: K-feldspar, Pl: plagioclase, LF : lithic fragments.

samples were collected from different horizons in two formations, mineral composition in a fixed size interval can largely be affected by the provenance.

In order to examine this fractional composition, two samples were selected from the F1 and the K2 groups. These two samples were collected from different 
localities and have different grain-size distributions with each other. On a thin section cut parallel to the lamination plane, the grain size was measured as a chord length of the grain by the Rosiwal method (Carver, 1971 p. 387). The grains of plagioclase and K-feldspar were discriminated by staining method (Bailey and Stevens, 1960). Approximately 3,000 grains along a steadfast traverse were identified and measured their chord lengths.

Thus obtained results in every size fractions are shown in Fig. 12. Two samples from the same group show similar systematic modal variations with grain-size. The lithic fragments increases with grain-size, and counterbalanced crystal constituents decrease. The ranges of variation seems to be greater in the K2 sample than that in F1.

The mineral compositions of the rest of the samples mode was conventionally obtained by counting of 1,000 points. The correlation between the mean grainsize and the mineral composition show marked contrast between the F1 and the K2 groups (Fig. 13). The F1 sandstones show a poorer size-control than the K2 sandstones. Such a good correlation demonstrated in the K2 group suggests the results of the hydraulic sorting with $\mathrm{H}$. E. during the sedimentation of every turbidite layers.
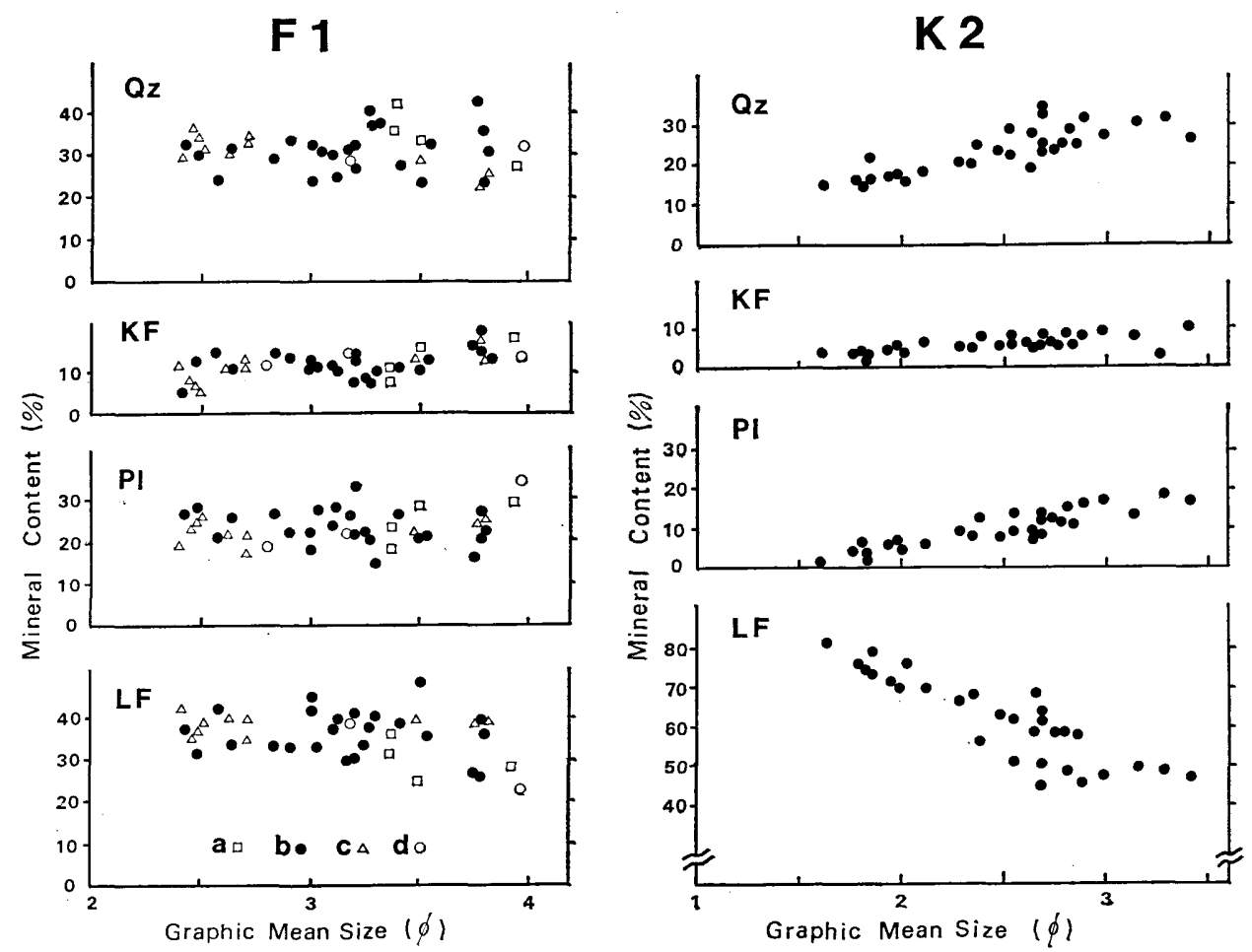

Fig. 13. Correlation between the mineral abundances and the mean grain-size of samples from F1 Formation (left) and from K2 Formation (right). The sample subgroups, a to d, are collected along the routes shown in Fig. 10. 


\section{B. Consistency of fractional composition}

The above-mentioned distinct size-control in the $\mathrm{K} 2$ sandstones are regarded as the results of hydraulic sorting of equivalent grains. Accordingly, the mineral composition in a fixed size interval is anticipated to be constant throughout the K2 formation. If it is rightful, the mineral composition of the other samples can be predicted using their grain-size distributions. In this case, the mineral composition of a sample is regarded as a function of the grain-size distribution of the sample and the consistent fractional composition.

Here we must reconfirm the geometrical definition of both mineral composition and grain-size distribution used in this study. The mineral composition of a sample is inspected by area-frequency by point-counting, while grain-size was given in length and the abundance was given in number-frequency. In order to combine the mineral composition with grain-size distribution, the frequency of

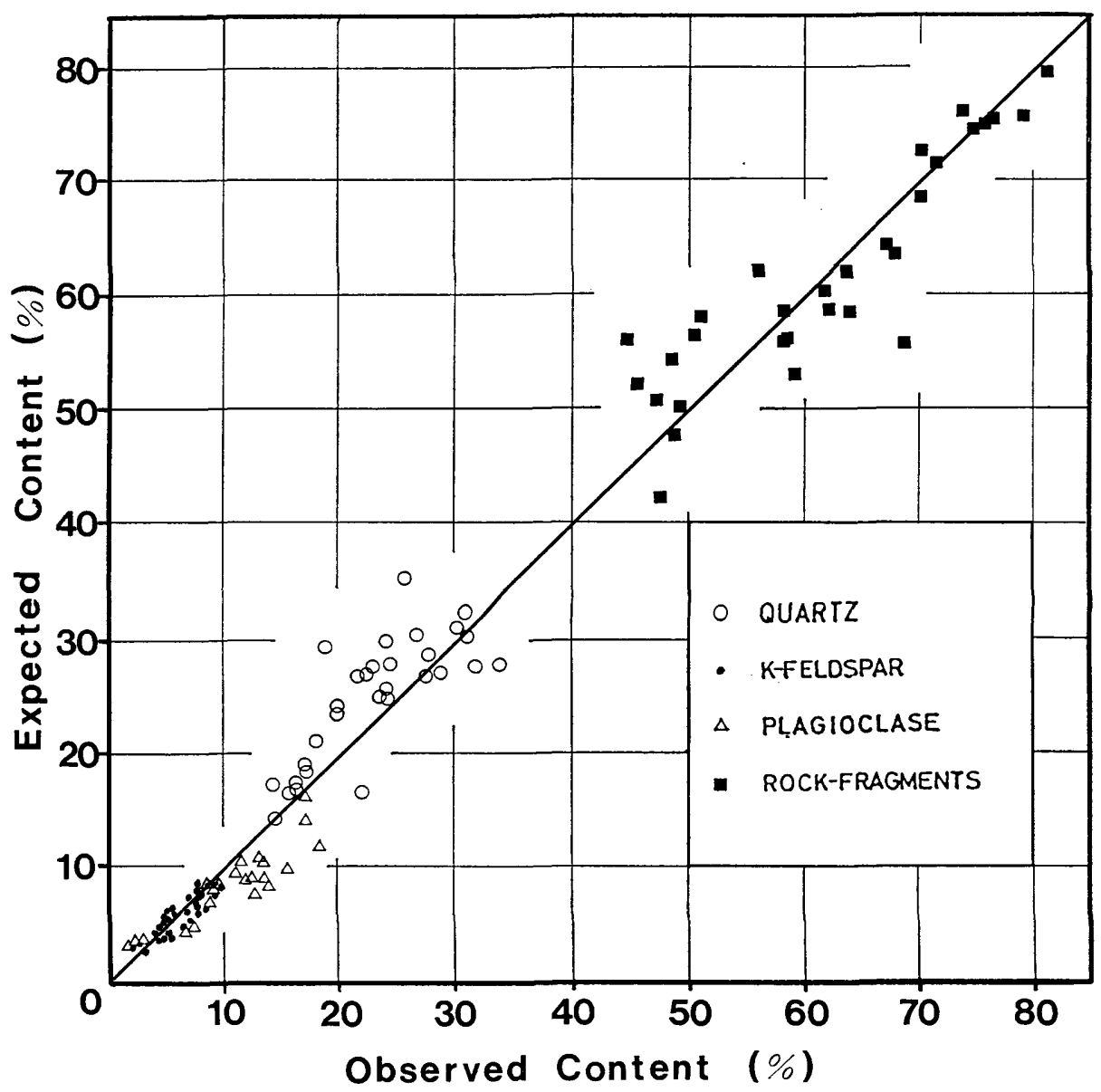

Fig. 14. The relationship between mineral contents obtained by point-counting (observed) and those estimated from the grain-size distribution of samples and consistent composition in a fixed size fraction (expected) for the sample group K2. 
the grain-size distribution should be translated from the number base to the area base. During the calculation, it is assumed that there are no difference in shape and orientation of grains as in the case of spherical grains. Then, the following functions can be introduced;

1. The probability of the traverse intercept by a grain is proportional to the grain-diameter on a thin section plane,

and

2. the area occupied by a grain on a thin-sectioned plane is proportional to the square measure of the grain-diameter.

Consequently, the mineral content in a sample is given by the area-frequency grain-size distribution combined with consistent fractional composition.

As the results, the calculated compositions of the $\mathrm{K} 2$ sandstone samples could well approximates the measured compositions (Fig. 14). This results also indicate that the effects of the grain-shape and preffered orientation can be neglected, because the grain-size was not given by a diameter but by a chord length.

This approximation demonstrates that H. E. was well realized during sedimentation of the turbidite layer of the K2 group. Since H. E. is realized throughout the sedimentation of the K2 sandstones, it is accepted that these sediments are derived from a common source material. It may be attributed to the sediments of every turbidite layer is derived from a homogeneous source, or fully mixed during transportation. The abundant clay matrix in the K2 sandstones also suggests the turbulent mixing during transportation.

On the other hand, poor size-control in the F1 sandstones shows that $\mathrm{H}$. E. could not be completed in sedimentation of more than a single layer. The regional deviation of compositions is not distinct when they are compared among sample subgroups collected from different routes (Fig. 13, left). Each sandstone beds might be derived from variable source, that is reconciled with their shallowmarine sedimentary facies.

\section{Discussions}

\section{A. Problems in application of hydraulic equivalence}

It has been noted by some investigators that the settling velocity distributions of different mineral species in a sample are different, and that the size distributions of some mineral particles do not coincide with those predicted from hydraulic equivalence. Such inconsistencies are exemplified by studied bed load samples from beach and dune sands (McIntyre, 1959; Hand, 1967), Tertiary fluvial sand (Briggs, 1965), cross-laminated sand (White and Williams, 1967) and placer deposits (Tourtelot, 1968).

It is apparent that in the traction load which contains grains of different shapes and densities, it is impossible to predict the size relationship among constituent minerals by the application of settling equivalence alone. Griggs and Rathbun (1969) and Slingerland (1977) tried to find an alternative equivalence involving factors such as grain size, shape, but no satisfactory results on equivalence were obtained. 
This is because for the traction load the H. E. concept does not mean the settling equivalence. For this reason, Burroughs (1985) developed an advanced model of entrainment equivalence for rolling or sliding grains on the bed. $\mathrm{He}$ showed a equivalent diameter as a function of grain density, shape and topographical situations.

More serious problem appears, however, in applying H. E. for isolated grains to that for grain populations. It is not correct to think that if only $\mathrm{H}$. E. was realized, all mineral species in a sample would show the same settling velocity distribution. In the case of an isolated grain, the trace of it in a fluid is described only by the equation of motion in principle, and the site of deposition is uniquely determined. When the turbulent effect were accounted, the locus of deposition can be determined statistically as the most probable value. Even in such case, the settling velocity distribution of the grain population of one mineral species will not necessarily be the same distribution as that of the other mineral species in a sediment sample. The reason may be explained as follows.

A case is considered where the source material is composed of various mineral species which have different settling velocity distributions. It is a common case in nature that the grains of one mineral species are abundant in the larger settling velocity intervals in the source, while another mineral species in smaller intervals. As a result, the former mineral species is more abundant in larger settling velocity intervals and less abundant in smaller intervals in the sediments. And the latter population will show a settling velocity distribution that is skewed towards smaller intervals.

\section{B. Consistent composition in a fixed settling velocity interval}

The relative abundance of settling grains of a given mineral species with a given settling velocity interval can be determined with two parameters. One is relative availability of the mineral grains in the system. The other is the selection of grains by fluid flow according to their settling velocities. When the settling velocity distribution is taken into consideration for this mineral grain population, these parameters come to be expressed as probability distributions. The relative abundance of this mineral grains is given by the product of these two probability vectors. It seems likely that the conventional approach for the sorting processes have failed because they had been involving only the latter probability.

Consequently it seems quite natural that the settling velocity distributions of mineral species are different in a sediment sample, even if the hydraulic equivalence has been realized. However, there appear another problems how can we ascertain only from sample examinations whether the hydraulic equivalence have been realized or not, or how to know laws governing the regional variation in mineral composition of sediments.

At least, there remains one clue; since the grains with the same settling velocity in suspension will not be distinguished with each other, and the mineral composition in a fixed settling velocity interval will not change during the transportation. If this composition was assumed to be maintained, we can recognize again the sorting processes from the this point of view which is an alternate 


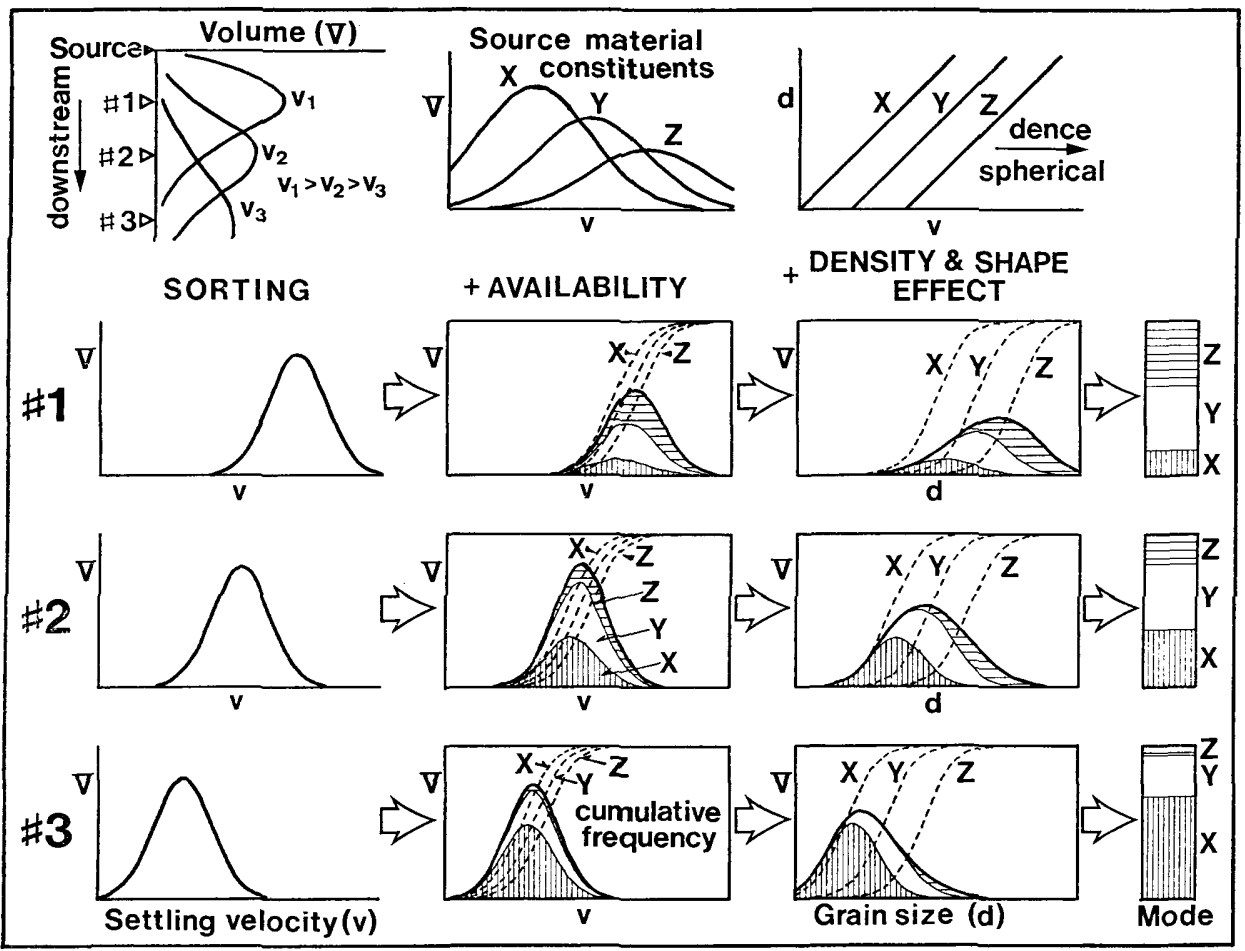

Fig. 15. Schematic illustration showing processes of hydraulic sorting during the transportation which brings about compositional variation of sediments (for details see text).

way of application of $\mathrm{H}$. E. .

The above considerations are best explained diagrammatically in Fig. 15. Suppose that the source material is a sediments composed of three mineral species (X, Y and Z), all of which have different shapes and densities (Fig. 15, upper right). That is these mineral species show different distributions of settling velocity, if they have the same grain-size distribution. Mostly, they also have the different availabilities in the source (Fig. 15, upper middle).

The diagrams in the left column show the hydraulic or aerodynamic sorting processes. In this case, grains of larger settling-velocity settles near the source, while those of smaller velocity in the distal area. The sediments of site \#1, proximal to the source, show larger mean velocity, and the mean velocity decreases downstream. The settling velocity distributions in the sediments at all sites are assumed to be normal distribution for simplicity of explanations.

When the availabilities of mineral species in the source are taken into consideration, the relative abundance of a certain mineral is given by the product of the hydraulically yielded amount (Fig. 15, left column) and its relative availability in any velocity fractions. At that time, the volumetric mineral composition in a fixed velocity interval is not deviated from that in the source. This composition is maintained during the transportation, and they are also the same in the sediments at any depositional site. Consequently, three mineral species show 
different settling velocity distributions in a sediment sample as shown by the cumulative frequency curve in the diagrams of middle column of this figure.

The relative abundance of a certain mineral in a sediment sample is given by the area under the density curve of the grain-size distribution density curve. The mineral composition is defined by these relative abundances. When the relationship between grain-size and velocity for each mineral species is introduced, the grain-size distribution is determined from the velocity distribution for each mineral species (Fig. 15, diagrams in the right column).

It has been often missed in the previous literatures to appreciate this availlability when $\mathrm{H}$. E. during the sedimentation is briefly studied. If the availability is tacitly ignored, we are lead to a specious idea that every mineral species will show an identical settling velocity distribution in a sediment sample. In such a case, curiosity was focued on only the density and shape effects, and H. E. was insufficiently argued.

Acknowledgements: I wish to express my sincere thanks to Emeritus Prof. Dr. Kametoshi Kanmera, Profs. Hakuyu Okada, Yujiro Ogawa, and Takeru Yanagi for valuable discussions and comments. The manuscript was largely benefited from critical review by Drs. R. S. J. Sparks and T. Pickering whom I gratefully acknowledge. Thanks are also due to Messrs. Hisao Sunouchi and Shin'ichi Iwano for the technical assistance.

\section{References}

BaIley, E. H. and Stevens, R. E. (1960) : Selective staining of K-feldspar and plagioclase on rock slabs and thin sections. Amer. Mineralogist, 45, 1020-1025.

Briggs, L. I. (1965) : Heavy mineral correlations and provenances. Jour. Sed. Petrol., $35,939-955$.

Burroughs, W. A. (1985) : The hydraulic equivalence of mica-discussion. Jour. Sed. Petrol., 55, 291-294.

CARver, R. E. (1971) : Holocene and late Pleistocene sediment sources, continental shelf off Brunswick, Georgia. Jour. Sed. Petrol., 41, 517-525.

COMMITTEE ON NOMENCLATURE OF PYROCLASTIC DEPOSITS IN HoKkaido (1972): Distribution of Quaternary pyroclastic deposits in Hokkaido. Hokk. Nat. Agric. Exp. Stn., Sapporo, Japan (in Japanese).

(1982): Volcanic ash in Hokkaido. Hokk. Nat. Agric. Exp. Stn., Sapporo, Japan (in Japanese).

Fisher, R. V. (1964): Maximum size, mean diameter, and sorting of tephra. Jour. Geophys. Res., 69, 341-355.

Folk, R. L. (1974) : Petrology of Sedimentary Rocks. Hemphill, Texas, $182 \mathrm{pp}$.

Galenhouse, J. S. (1971) : Point Counting. in CARver, R. E. ed., Procedure in Sedimentary Petrology. Wiley Interscience, New York, 385-408.

Griggs, N. S. and RATHBUN, R. E. (1969) : Hydraulic equivalence of minerals with a consideration of the reentrainment process. U.S. Geol. Survey Prof. Paper, 650-B, B77-80.

HAND, B. M. (1967) : Differentiation of beach and dune sand, using settling velocities of light and heavy minerals. Jour. Sed. Petrol., 37, 514-520.

Hesse, R. (1965) : Herkunft und Transport der Sedimente in bayerichen Flyschtrog. Z. Deutch. Geol. Ges., 116, 403-426. 
Katsui, Y. (1959) : On the Shikotsu Pumice-fall Deposit, Special reference to the activity just before the depression of the Shikotsu Caldera. Bull. Volc. Soc. Japan, 2nd ser., 4, 33-48 (in Japanese).

KATSUI, Y. and MURASE, T. (1960): Some consideration on the activity of the Shikotsu Volcano. Jour. Geol. Soc. Japan, 66, 631-638 (in Japanese).

Kittleman, L. R. (1973): Mineralogy, correlation, and grain-size distributions of Mazuma tephra and other postglacial pyroclastic layers, Pacific northwest. Geol. Soc. Am. Bull., 84, 2957.

MAChIDA, H. and ARAI, F. (1976): The widely distributed tephra. Kagaku (Science), 46, 339-347, Iwanami, Tokyo (in Japanese).

MCINTYRe, D. D. (1959): The hydraulic equivalence and size distribution of some mineral grains from a beach. Jour. Geology., 67, 278-301.

Mitzmager, A. SAdAN, A. and Shelef, M. (1964): Rapid computation of settling or rising velocity of spherical particles in fluid media. Brit. Chem. Eng., 9, 314-315.

Obata, I. and MATSUmoto, T. (1977) : Correlation of the Lower Cretaceous Formations in Japan. Sci. Rep., Dept. Geol., Kyushu Univ., 23, 165-179, (in Japanese).

Rittenhouse, G. (1943): The transportation and deposition of heavy minerals. Geol. Soc. Am. Bull., 54, 1725-1780.

Rouse, H. (1938) : Fluid mechanics for hydraulic engineers. chap. XI, Dover, N.Y.

RubEY, W. W. (1933): The size distributions of heavy minerals within a waterlaid sandstone. Jour. Sed. Petrol., 3, 3-29.

SLINGERLAND, R. L. (1977): The effects of entrainment on the hydraulic equivalence relationship of light and heavy minerals in sands. Jour. Sed. Petrol., 47, 753-770.

TAIrA, A. and Scholle, P. A. (1977): Design and calibration of a photo-extinction settling tube for grain size analysis. Jour. Sed. Petrol., 47, 1347-1360.

Tourtelot, H. A. (1968): Hydraulic equivalence of grains of quartz and heavier minerals, and implications for the study of placer. U.S. Geol. Survey Prof. Paper, 594-F, 1-13.

WALKER, G. P. L. (1971) : Grain size characteristics of pyroclastic deposits. Jour. Geol., 79, 696-714.

Walker, G. P. L. and Croasdale, R. (1971) : Two plinian-type eruptions in the Azores. Geol. Soc. London Jour., 127, 17-55.

WALKeR, G. P. L., Wilson, L. and BoWELL, E. L. G. (1971) : Explosive volcanic eruptions -I, the rate of fall of pyroclastics. Geophys. J. R. astr. Soc., 22, 377-383.

White, J. R. and Williams, E. G. (1967): The nature of a fluvial process as defined by settling velocities of heavy and light minerals. Jour. Sed. Petrol., 37, 530-539.

WILSON, L. and HUANG, T. C. (1979): The influence of shape on the atmospheric settling velocity of volcanic ash particles. Earth Planet. Sci. Lett., 44, 311-324.

Woods, A. W. (1988): The fluid dynamics and thermodynamics of eruption columns. Bull. Volcanol., 50, 169-193. 